\title{
A study on the success of group formation and cohesiveness in virtual teams using computer- mediated communications
}

\author{
Eliel Melon, Nova Southeastern University, melon@nova.edu \\ Yair Levy, Nova Southeastern University, levyy@nova.edu \\ Laurie P. Dringus, Nova Southeastern University, laurie@nova.edu
}

\begin{abstract}
While the Internet is a major business tool nowadays, individuals are still challenged to form teams and collaboration virtually. To evaluate the success of team formation in a virtual setting, this research study assessed the role of different computer-mediated communications (CMC) employed on the success of team formation measured by task performance (TP), team cohesiveness (TC), computer skills (CS) and social bond (SB), while assessing the differences on such relationships when controlled for gender, age, education level, academic major, as well as academic year. This research used analysis of variance (ANOVA) and analysis of covariance (ANCOVA) to address the hypotheses proposed. Using three teams and 140 participants, the results indicated that there is a significance difference in the role of CMC levels employed on the level of perception of CS in team formation. Also, there is a significance difference in the role of $C M C$ levels employed on the levels of TP, when controlled for gender. In addition, there is a significance difference in the role of CMC levels employed (No-CMS/F2F, OLS, \& OLS+SNS) on the levels of CS, when controlled for education, academic major and academic year. The results of this study contribute to the body of knowledge by helping organizations identify ways to support effective team formations.
\end{abstract}

Keywords: Team formation, computer-mediated communications in teams, social networking sites in teams, virtual teams, team cohesion, task performance

\section{Introduction}

Individuals around the world are using social networking sites (SNS's) such as Facebook®, and Twitter® to interact with friends or family. Experts who responded to a survey about the future of the Internet said, "the use of email, social networks, and other online tools offers low-friction opportunities to create, enhance, and rediscover social ties that make a difference in people's lives" (Quitney \& Rainie, 2010, p. 1). College students are heavy users of the Internet, and communication over SNS has become standard among them. The role of the Internet in the lives of individuals goes beyond being merely a method of communication; it has become an integral part of their daily lives and their social interactions (McMillan \& Morrison, 2006). 
Weaver and Morrison (2008) defined an SNS as a Website that "allows users to post their profiles and create personal networks for exchanging information with other users" (p. 97). The role of SNS is to enable users to articulate and make themselves visible to others via these social networks (Boyd \& Ellison, 2007). Moreover, it appears that forming teams in virtual environments both for work and academic purposes appear to be challenging (Agustín-Blas et al., 2011; Anagnostopoulos, Becchetti, Castillo, Gionis, \& Leonardi, 2012). Thus, this research study was set forth to investigate the role of CMC levels employed in the success of team formation. According to Christodoulopoulos and Papanikolaou (2007a), "team formation may be used in different contexts, such as in a computer-supported collaborative learning (CSCL) context for grouping users who could potentially benefit from cooperation based on their complementariness of knowledge/skills or competitiveness, or forming groups around problems with specific requirements" (p. 57). Understanding how SNS technology can be used to facilitate the difficult task of forming virtual teams will provide better strategies for supporting team cohesiveness and team performance (Shin \& Park, 2009). Hogg and Tinsdale (2001) reported that in workgroups, members' ability to get along with each other (i.e., cohesiveness) is critical to group well-being and task performance. According to Salisbury, Carte, and Chidambaram (2006), "the importance of developing such intra-team cohesiveness has proven to be particularly relevant in cases where members are not familiar with each other" (p. 148). This is also the case for virtual teams, and it appears that additional work in assessing factors and tools that can help fertilize virtual teams formation is highly needed (Malhotra, Majchrzak, \& Rosen, 2007; Maynard \& Mathieu, 2012). Therefore, the research problem that this research study addressed was the difficulty of team formation and collaboration between individuals in virtual teams (Fransen, Kirschner, \& Erkens, 2011; Liccardi et al., 2007; Malhotra et al., 2007; Ounnas, 2008). The main goal of this research study was to assess the role of different CMC levels employed (No-CMC/F2F, Online Learning Systems (OLS), \& OLS+SNS) on the success of team formation as measured by the level of task performance (TP), team cohesiveness (TC), social bond (SB), and computing skills (CS), while assessing if there are any differences on such relationships when controlled for demographic information such as gender, age, education level, academic major, as well as academic year.

\section{Review of Literature}

The growth of the Internet, coupled with the technological advancements of the last few years, triggered the explosive development of CMC. According to Breakenridge (2008), SNS comes down to the individual; that person has a social network and s/he wants to try to organize friends, essentially because communication is so much easier and quicker these days. Most CMC cater primarily to individualistic or personal motivations and goals (e.g. they allow users to store their pictures, bookmarks, or videos); they facilitate one-to-one or one-to-many communication, and the publishing of ideas (Wever, Mechant, Veevaete, \& Hauttekeete, 2007). A CMC, while it enables personal motivation, creates a new kind of almost effortless cooperation. It creates weak ties between casual acquaintances who did not previously have any cooperative action plan or altruistic intention. The success of Web2.0 services reveals the user's hybrid motivation, where the individualization of the user's goals meets the opportunity of sharing personal expression in a public sphere (Wever et al., 2007). These kinds of tools can influence the success of group formation in virtual teams. 


\section{Virtual Teams}

In terms of virtual teams, the literature indicates that this concept has grown and there has been a proliferation of definitions (Martins, Gilson, \& Maynard, 2004). According to Lipnack and Stamps (1997), "it was not until the 1990s that the word "virtual" made it into the headlines on a regular basis" (p. 5). Miles and Snow (1986) stated that a virtual team is an evolutionary form of a network organization. The concept is enabled by advances in ICT (Davidow \& Malone, 1992; Jarvenpaa \& Ives, 1994). Virtual implies permeable interfaces and boundaries; project teams that rapidly form, reorganize, and dissolve when the needs of a dynamic marketplace change; and individuals with differing competencies who are located across time, space, and cultures (Kristof, Brown, Sims, \& Smith, 1995; Mowshowitz, 1997). Today, virtual teams have become almost indispensable to organizations (Paul \& Ray, 2009). According to Paul and Ray (2009), "global virtual teams have now become critical mechanisms for integrating information, making decisions, and implementing plans around the world" (p. 1). In this era of globalization and everchanging environments, distributed working groups need to develop a competitive advantage. One problem a virtual team appear to remain facing is its formation in this digital environment. People have differences, and in a virtual environment, much of the time, people do not see each other's faces. For this reason, when a virtual team is created, it cannot be determined in advance if the team formation will lead to success.

\section{Team Cohesiveness (TC)}

Munkvold and Zigurs (2007) stated, "virtual teams are formed in response to specific needs and typically must perform quickly" (p. 287). They need a rapid start-up, and usually individuals in these virtual worlds are people who have no prior knowledge of the others on the team and they need to work together immediately (Munkvold \& Zigurs, 2007). Identifying the correct people to solve a problem efficiently or collaborate with others is a challenging task (Liccardi et al., 2007). Teams are formed for the purpose of performing a task or a series of related tasks (Guzzo \& Salas, 1995). Organizations make great efforts to find ways to configure work done in face-toface teams, and now the formation of virtual teams faces a new level of complexity (London, 2001). Schwanda et al. (2011) stated that "team cohesiveness is a vital social dynamic that is difficult to achieve in virtual teams" (p. 709). They also indicated that members of highly cohesive groups tend to be more satisfied with their experience than those in less cohesive groups. Powell et al. (2004) stated that "high levels of communication early in the life of virtual teams foster team cohesiveness. High levels of cohesiveness reduce barriers to communication and are instrumental in promoting a virtuous cycle of cooperation" (p. 16). Jarvenpaa and Leidner (1999) indicated that early communication and interaction have lasting effects on trust in the virtual environment.

\section{Social Bond (SB)}

Social bond theory has remained a major paradigm since its introduction in 1969 (Pratt, Franklin, \& Gau, 2011). According to Hirschi (1969), virtually all existing criminological theories began with a faulty fundamental premise: that criminal behavior requires the creation of criminal motivation. Hirschi (1969) postulated that all of us possess the drive to act in the kinds of selfish and aggressive ways that lead to criminal behavior and that it is part of our innate human nature. The question that Hirschi (1969) asked was, why the rest of the population does not participate in that criminal behavior? According to Pratt et al. (2011), "for Hirschi, the answer could be found 
in the bonds that people form to prosocial values, prosocial people, and prosocial institutions" (p. 58). It is these SBs that end up in controlling human behavior when they are tempted to engage in criminal or deviant acts (Hirschi, 1969). These bonds come in four interrelated forms: attachment, commitment, involvement, and belief (Pratt et al., 2011). Attachment, according to Hirschi (1969), refers to the level of psychological affection one has for prosocial others and institutions. Pratt et al. (2011) explained that, "for Hirschi, parents and schools were of critical importance in this regard, where youths who form close attachments to their parents and schools will, by extension, experiment greater levels of social control" (p. 58). Commitment is the second type of SB where people value social relationships, which they would not want to risk jeopardizing by committing criminal or deviant acts (Hirschi, 1969). Hirschi (1969) explained that people are less likely to misbehave when they know that they have something to lose (Pratt et al., 2011). According to Pratt et al. (2011), involvement relates to the opportunity costs associated with how people spend their time. If people are spending their time engaged in some form of prosocial activity, then they are not, by definition, spending their time engaged in antisocial activity (Hirschi, 1969). Pratt et al. (2011) described the final type of social bond identified by Hirschi (1969):

as the degree to which one adheres to the values associated with behaviors that conform to the law: the assumption being that the more important such values are to a person, the less likely he or she is to engage in criminal/deviant behavior. (p. 59)

\section{Task Performance (TP)}

According to Triplett (1898), children showed more effort on a coactive task when other children were present, compared with situations where they were performing alone. While it is generally accepted that virtual teamwork has considerable cost and flexibility benefits, there is some question whether the benefits outweigh possible performance losses arising from virtual versus F2F work (Corbitt, Gardiner, \& Wright, 2004). According to Corbitt et al. (2004), "computer mediated groups tend to perform better than $\mathrm{F} 2 \mathrm{~F}$ groups on idea generation tasks but worse on more complex tasks with computer-mediated groups typically having longer task completion times" (p. 3). Optimal team composition in virtual settings may be different from traditional teams (Turel \& Zhang, 2010). Sproull and Kiesler (1986) stated that virtual teams lack the timely verbal cues and facial expressions that prevail in face-to-face team interactions and, as such, find it more difficult to become cohesive and to perform well. According to Chidambaram and Tung (2005), virtual teams often present heightened levels of social loafing and frequently struggle to build trust and relationships among team members (Jarvenpaa, Knoll, \& Leidner, 1998), which are crucial for team performance (Lin et al., 2008). Given these attributes, whereas in traditional teams loose leadership may suffice, strong emergent leadership may be required in virtual settings to prevent the prevalent phenomenon of social loafing that will affect a virtual team's TP (Chidambaram \& Tung, 2005).

\section{Computing Skills (CS)}

In today's computing environment, "the bottom line is not how good information systems (IS) are, but rather how well they are used" (Torkzadeh \& Lee, 2003, p. 607). As computing technology is used in one form or another in all fields, it is imperative that individuals have proficiency in the area of computing technologies (Hanebutte, 2013). According to Hanebutte (2013), "the level of computing technology literacy does not appear as high as expected from 
industry, and individuals are not as comfortable with the use of computing equipment as they were a few years ago" (p. 87). Effective use of computing technology is considered by Torkzadeh and Lee (2003) a "major determinant of economic growth, competitive advantage, productivity, and even personal competency" (p. 607). Computing skills influence how well computing technology is used by individuals. As an example, individuals understand how to use a Web browser. However, according to Hanebutte (2013), beyond the knowledge of understanding how to use a Web browser, there is often very little comprehension about how Web pages are transported and displayed. According to Fernandez (2009), "successful computing professionals will need personal skills and developing the personal skills in organizations will be very important" (p. 111).

\section{Research Methodology}

This study was exploratory using survey methodology to assess the role of the three different CMC levels employed on the success of team formation as measured by the level of four aforementioned constructs (TP, TC, SB, \& CS), while assessing if there are any differences on such relationships when controlled for some demographic variables. Three groups were compared: Group A (F2F), Group B (OLS), and Group C (OLS+SNS). Group A included individuals from an on-campus course, forming groups F2F in class to work on some tasks, and will serve as the control group for the proposed research. Group B included individuals from an OLS, forming groups assigned by the professor in virtual teams using a traditional discussion board online to work on the same tasks in the system. Group $\mathrm{C}$ included individuals from an OLS, forming groups in virtual teams using SNS to work on the same tasks in the system using a discussion board provide by the OLS. The hypotheses are represented in the conceptual model for team formation success (Figure 1).

The hypotheses that this study addressed were (in the null form):

H1: There will be no significant difference in the role of CMC levels employed (No$C M C / F 2 F, O L S, O L S+S N S$ ) on the level of $T P$ in team formation.

H2: There will be no significant difference in the role of CMC levels employed ( $\mathrm{No}$ $C M C / F 2 F, O L S, O L S+S N S)$ on the level of perception of cohesion in team formation.

H3: There will be no significant difference in the role of CMC levels employed (No$C M C / F 2 F, O L S, O L S+S N S)$ on the level of perception of $S B$ in team formation.

H4: There will be no significant difference in the role of CMC levels employed (No$C M C / F 2 F, O L S, O L S+S N S)$ on the level of perception of $C S$ in team formation.

H5: There will be no significant difference in the role of CMC levels employed (No$C M C / F 2 F, O L S, O L S+S N S$ ) on the success of team formation as measured by the levels of $T P$, perception of cohesion, perception of $S B$ and perception of $C S$ when controlled for demographic information such as gender, age, education level, academic major, as well as academic year.

More specifically: 
H5a: There will be no significant difference in the role of CMC levels employed (No$C M C / F 2 F, O L S, O L S+S N S$ ) on the levels of $T P$, perception of cohesion, perception of $S B$, and perception of $C S$ when controlled for gender.

H5b: There will be no significant difference in the role of CMC levels employed (No$C M C / F 2 F, O L S, O L S+S N S$ ) on the levels of $T P$, perception of cohesion, perception of $S B$, and perception of $C S$ when controlled for age.

H5c: There will be no significant difference in the role of CMC levels employed (No$C M C / F 2 F, O L S, O L S+S N S$ ) on the levels of $T P$, perception of cohesion, perception of $S B$, and perception of $C S$ when controlled for education level.

H5d: There will be no significant difference in the role of CMC levels employed (No$C M C / F 2 F, O L S, O L S+S N S$ ) on the levels of $T P$, perception of cohesion, perception of $S B$, and perception of $C S$ when controlled for academic major.

H5e: There will be no significant difference in the role of CMC levels employed (No$C M C / F 2 F, O L S, O L S+S N S$ ) on the levels of $T P$, perception of cohesion, perception of $S B$, and perception of $C S$ when controlled for academic year.

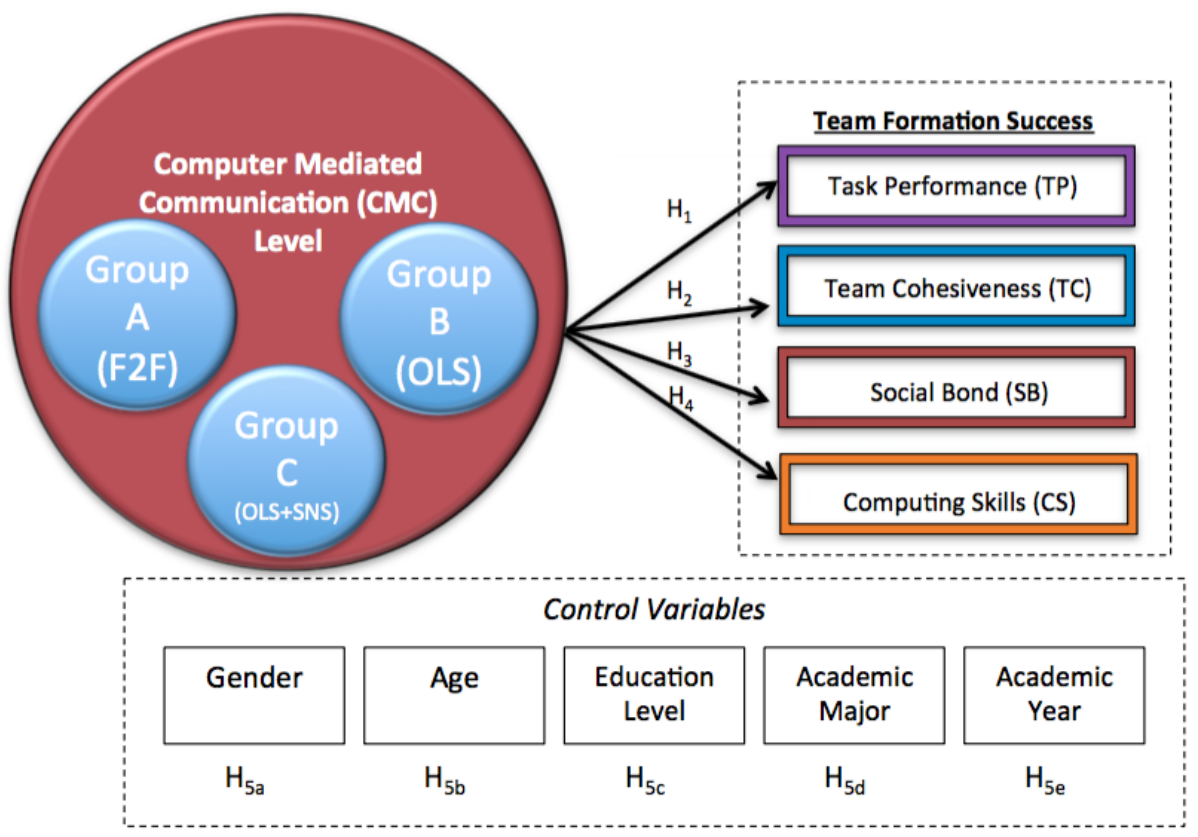

Figure 1. Conceptual Model for Team Formation Success

\section{Results}

There were 143 responses received from the survey respondents. Before the collected data could be analyzed, pre-analysis data screening was performed to detect irregularities with the collected data. According to Levy (2006), pre-analysis data screening is performed to ensure the accuracy of the data collected, to eliminate cases with response-set, check for missing data, and to deal with extreme cases or outliers. For this study, data accuracy was not an issue as the Web-based survey instrument was designed to allow only a single valid answer for each question. 
Additionally, data collected did not require any manual input as it was submitted into a Web form directly into a spreadsheet prior to the analyses. The issue of missing data was also not present for this study as the Web-based survey instrument was constructed in a way that all items were required. To address the issue of response-sets, a visual inspection of all responses was performed to identify cases that had the same response to all of the survey items. Response-set bias produces pattern of responses that may not correctly correspond to the true stat of affairs (Mangione, 1995). According to Kerlinger and Lee (2000), it is recommended that researchers do analysis of data for potential response-sets, and consider the elimination of any such sets from the research prior to the main data analysis. In this study, there were three response-set cases in the collected data and they were eliminated due to their severity of including the same score on all measured items, indicating the participants did not faithfully answered the survey. Another main reason for pre-analysis data screening was to deal with extreme cases or outliers. In order to address multivariate extreme cases, Mahalanobis Distance analysis was performed. No extreme cases were found in the collected data.

After completion of the pre-analysis data screening, 140 responses remained for analysis, with demographics that is similar to that of the general sample targeted. Of which, 111 or $79.3 \%$, were completed by females and 29 or $20.7 \%$ were completed by males. Analysis of the ages of respondents indicated that 127 or $90.8 \%$ were between 19 to 29 . Respondents with associates degrees are $33.6 \%$ of the population while bachelor's degrees are $31.4 \%$. Overall, 98 respondents or $70 \%$ had a university degree prior studying in the program that they have enrolled in the School of Health Professions, 92 or $65.7 \%$ were enrolled in an undergraduate program and 85 or $60.7 \%$ had one year or less in the program that they have enrolled. Details of the demographics of the population are presented in Table 1. As noted before, the population was randomly divided into three groups. This proposed research compared the three groups: Group A, Group B, and Group C. Details of the demographics of the population of each group are presented in Table 2. 
Table 1. Descriptive Statistics of Population $(\mathrm{N}=140)$

\begin{tabular}{lll}
\hline Item & Frequency & Perce \\
\hline Gender & & \\
Male & 29 & $20.7 \%$ \\
Female & 111 & $79.3 \%$
\end{tabular}

Age

18 or under

19 to 24

25 to 29

30 to 34

35 to 39

40 to 44

45 to 54

55 to 59

60 or older

\section{Academic Level}

High school diploma

Associates degree

Bachelor's degree

Master's degree

Professional degree

Doctoral degree

\section{Program Enrolled}

Undergraduate

Graduate

Years in the program

of study

1 year or less

85

2 to 5 years

54

6 to 9 years

10 years or longer
42

95

32

5

2

1

$65.7 \%$

$34.3 \%$

$0 \%$

$67.9 \%$

$22.9 \%$

$3.6 \%$

$1.4 \%$

$0.7 \%$

$2.9 \%$

$0 \%$

$0.7 \%$

$30.0 \%$

$33.6 \%$

$31.4 \%$

$4.3 \%$

$0 \%$

$0.7 \%$

$60.7 \%$

$38.6 \%$

$0 \%$

$0.7 \%$ 
Table 2. Descriptive Statistics for each group in population

\begin{tabular}{|c|c|c|c|c|c|c|}
\hline & $\begin{array}{l}\text { Group A } \\
(\mathbf{N}=44)\end{array}$ & & $\begin{array}{l}\text { Group B } \\
(\mathrm{N}=47)\end{array}$ & & $\begin{array}{l}\text { Group C } \\
(\mathrm{N}=49)\end{array}$ & \\
\hline Item & Frequency & $\begin{array}{l}\text { Percentage } \\
(\%)\end{array}$ & Frequency & $\begin{array}{l}\text { Percentage } \\
\text { (\%) }\end{array}$ & Frequency & $\begin{array}{l}\text { Perc } \\
(\%)\end{array}$ \\
\hline \multicolumn{7}{|l|}{ Gender } \\
\hline Male & 14 & $31.8 \%$ & 5 & $10.6 \%$ & 10 & $20.4^{c}$ \\
\hline Female & 30 & $68.2 \%$ & 42 & $89.4 \%$ & 39 & 79.6 \\
\hline \multicolumn{7}{|l|}{ Age } \\
\hline 18 or under & 0 & $0 \%$ & 0 & $0 \%$ & 0 & $0 \%$ \\
\hline 19 to 24 & 35 & $79.5 \%$ & 24 & $51.1 \%$ & 36 & $73.5^{\circ}$ \\
\hline 25 to 29 & 7 & $15.9 \%$ & 18 & $38.3 \%$ & 7 & $14.3^{c}$ \\
\hline 30 to 34 & 1 & $2.3 \%$ & 2 & $4.3 \%$ & 2 & $4.1 \%$ \\
\hline 35 to 39 & 0 & $0 \%$ & 0 & $0 \%$ & 2 & $4.1 \%$ \\
\hline 40 to 44 & 0 & $0 \%$ & 1 & $2.1 \%$ & 0 & $0 \%$ \\
\hline 45 to 54 & 1 & $2.3 \%$ & 2 & $4.3 \%$ & 1 & $2.0 \%$ \\
\hline 55 to 59 & 0 & $0 \%$ & 0 & $0 \%$ & 0 & $0 \%$ \\
\hline 60 or older & 0 & $0 \%$ & 0 & $0 \%$ & 1 & $2.0 \%$ \\
\hline
\end{tabular}

\section{Academic Level}

High school diploma $\quad 26$

Associates degree

Bachelor's degree

Master's degree

Professional degree

Doctoral degree

Program Enrolled

Undergraduate

Graduate

38

6

Years in the program of study

1 year or less

22

2 to 5 years

22

6 to 9 years

0

10 years or longer
$86.4 \%$

$13.6 \%$

24

23

$\begin{array}{ll}59.1 \% & 16 \\ 29.5 \% & 3 \\ 11.4 \% & 22 \\ 0 \% & 6 \\ 0 \% & 0 \\ 0 \% & 0\end{array}$

$34.0 \%$

$6.4 \%$

$46.8 \%$

$12.8 \%$

$0 \%$

$0 \%$

$51.1 \%$

30

$61.2 \%$

$48.9 \%$

19

$38.8 \%$
$0 \%$

$63.3 \%$

$34.7 \%$

$0 \%$

$0 \%$

$2.0 \%$ 
The study used Principal Component Analysis (PCA) to uncover how many components to retain and interpret and validate the construct measures. The Statistical Package for the Social Sciences (SPSS) software was used to run the PCA for the extraction of components to provide variances of underlying factors (Mertler \& Vannatta, 2013). Using Varimax rotation via PCA this study initially extracted as many factors as indicated by the data (Child, 2006). The results of the PCA factor analysis suggested that four factors with a cumulative variance of $82.79 \%$ should be retained. Using the factor loadings, survey items were scrutinized for low loadings $(<0.4)$ or for medium to high loadings ( 0.4 to 0.6 ) on the four factors. The results of this review indicated that three items could be eliminated from further analysis due to low factor loadings. Consequently, the final analysis excluded one item of SB and two items of TC. For the SB, SB1 item was removed. For the TC, TC1 and TC3 were removed. Table 3 presents the finalized rotated component matrix of SPSS using Equamax as the rotation method with four components.

Table 3. Rotated Component Matrix using Equamax as the rotation method

\begin{tabular}{lllll}
\hline & Component & 2 & 3 & 4 \\
\hline TP2 & .841 & .265 & .169 & .337 \\
TP3 & .803 & .275 & .212 & .359 \\
TP1 & .793 & .302 & .264 & .314 \\
TP4 & .786 & .272 & .226 & .351 \\
TP5 & .743 & .255 & .240 & .422 \\
SB5 & .289 & .807 & .175 & .256 \\
SB3 & .166 & .795 & .140 & .351 \\
SB7 & .240 & .778 & .264 & .291 \\
SB2 & .224 & .730 & .273 & .362 \\
SB6 & .361 & .704 & .340 & .272 \\
SB4 & .503 & .593 & .182 & .361 \\
CS3 & .049 & .146 & .900 & .151 \\
CS1 & .086 & .127 & .865 & .136 \\
CS5 & .216 & .216 & .851 & .143 \\
CS2 & .226 & .267 & .841 & .098 \\
CS4 & .371 & .163 & .730 & .236 \\
TC6 & .375 & .190 & .065 & .836 \\
TC5 & .138 & .376 & .225 & .759 \\
TC4 & .456 & .321 & .182 & .650 \\
TC2 & .518 & .422 & .189 & .566 \\
\hline & & & & \\
\hline
\end{tabular}

As part of the data analysis, the reliability of the four constructs that made the Team Formation was verified using Cronbach's Alpha (Cronbach, 1951). Gefen, Straub, and Boudreau (2000) defined Cronbach's Alpha as the commonly used measure for the concept of reliability, for a set of two or more construct indicators (or survey items). According to Boudreau, Gefen, and Straub 
(2001) as well as Straub (1989), Cronbach's Alpha levels of 0.7 and above have been reported to indicate strong reliability for the constructs. The Cronbach's Alpha analysis indicated that all items supported the reliability of all factors. Furthermore, the Cronbach's Alpha of each factor was 0.901 or higher, indicating very high reliability. Table 4 provides the outcome of this analysis.

Table 4. Cronbach's Alpha Reliability Analysis

\begin{tabular}{lll}
\hline Team Formation & No. of Items & Cronbach's Alpha \\
\hline Task Performance (TP) & 5 & 0.969 \\
Team Cohesiveness (TC) & 4 & 0.901 \\
Social Bond (SB) & 6 & 0.943 \\
Computing Skills (CS) & 5 & 0.934 \\
\hline
\end{tabular}

A one-way analysis of variance (ANOVA) and a one-way analysis of covariance (ANCOVA) were used to analyze the hypotheses. The study used ANOVA to analyze H1, H2, H3, and H4. Table 5 provides an overview of the study results, including the mean square scores of the constructs for the groups along with the ANOVA results. Calculating the means squares for every construct between groups and within groups SPSS obtained a significance of the F ratio or $p$ value for TC was 0.224 that tells that there is no significance difference between groups. For $\mathrm{SB}$, the significance of the $\mathrm{F}$ ratio or $\mathrm{p}$ value was 0.121 . This also tells that there is no significance difference between groups but also tells that additional research with this construct will be needed. TP also does not have a significance difference between groups. The significance of the F ratio or $p$ value was 0.740 . Finally, for CS SPSS obtained a significance of the F ratio or $p$ value of 0.039 . This construct has a significance difference.

Table 5. ANOVA Results for Team Formation

\begin{tabular}{ccll}
\hline Constructs & $\begin{array}{c}\text { Mean Square between } \\
\text { groups }\end{array}$ & F & SNOVA \\
\hline TC & 3.496 & 1.511 & 0.224 \\
SB & 4.100 & 2.146 & 0.121 \\
TP & 0.659 & 0.302 & 0.740 \\
CS & 5.545 & 3.329 & 0.039 \\
\hline$*-p<0.05, * *-p<0.01, * * *-p<0.001$ & & \\
\hline
\end{tabular}

Looking at all constructs and their results, this study determines that the construct of Computing Skills (CS) has the most significance difference, compared to the other ones. Figure 2 presents the means and standard deviations of the aggregated composite score. ANCOVA was used to analyze H5. According to Mertler and Vannatta (2013), "ANCOVA is similar to one-way analysis of variance (ANOVA) in that two or more groups are being compared on the mean of 
some dependent variable, but ANCOVA additionally controls for a variable (covariate) that may influence the dependent variable" (p. 15). Looking at the results of the analysis, it was determined that gender was significance when compared with the other ones using TP Means as the dependent variable with a $p$ value of 0.039 . Noticed that because education had a $p$ value of 0.103 with TP Means as the dependent variable, more research can be done in this area. Also, Academic Major using CS Means as the dependent variable was the most significance covariate when compared with the other ones, with a $p$ value of 0.002 . Education and Academic Year using CS Means as the dependent variable were significance also with a $p$ value of 0.034 and $p$ value of 0.016 respectively. Table 6 provides the outcome of the ANCOVA analysis. Moreover, summary of all the results of the hypotheses are outlined in Appendix A.

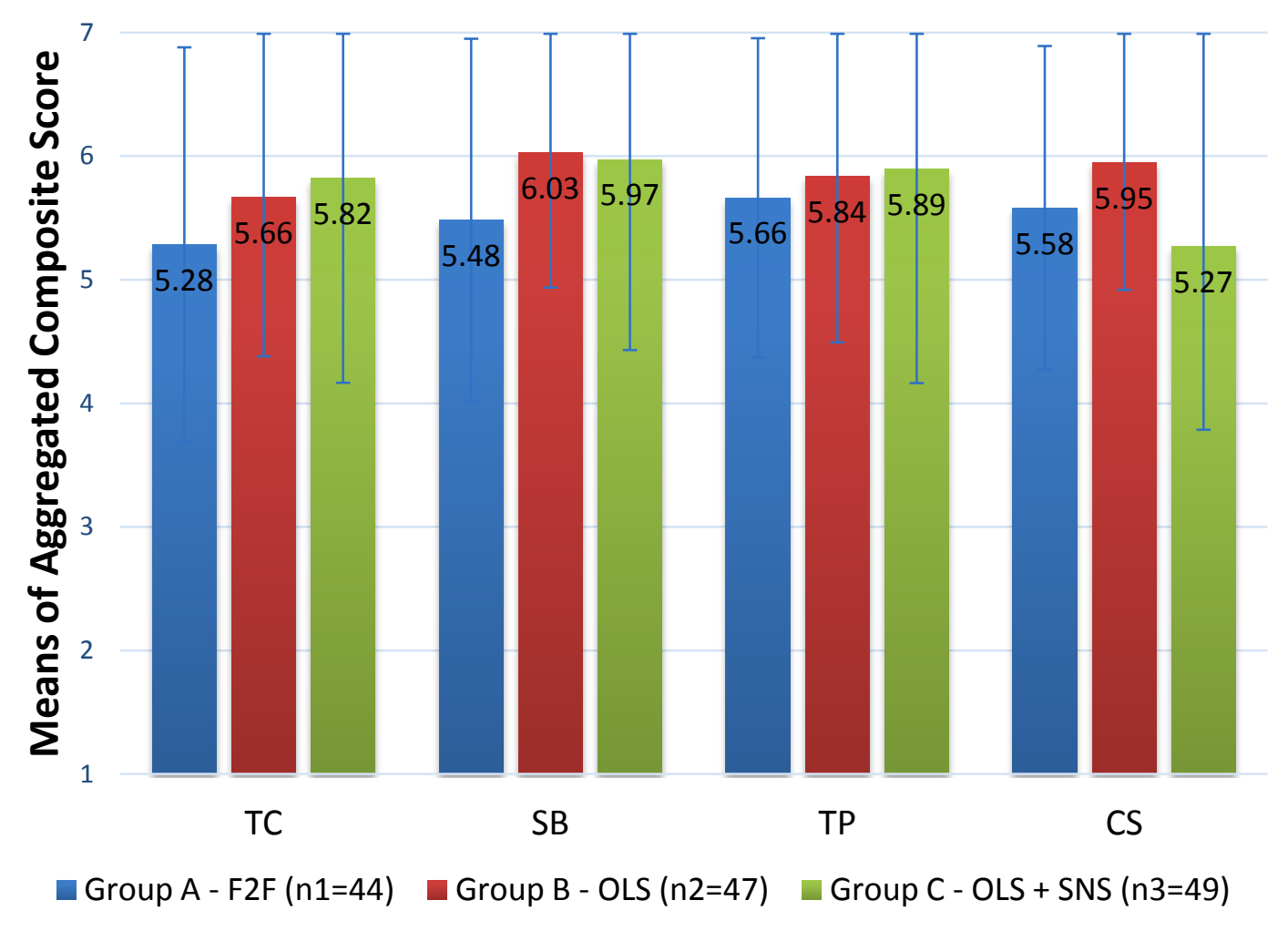

Figure 2. Figure for the Means and Standard Deviations of Aggregated Composite Score 
Table 6. ANCOVA Results for Team Formation and Demographics Covariates

\begin{tabular}{|c|c|c|c|c|c|c|c|c|c|c|}
\hline \multirow[b]{3}{*}{ Demographics } & \multicolumn{10}{|c|}{ ANCOVA } \\
\hline & \multicolumn{3}{|c|}{ TP Means (DV) } & \multicolumn{2}{|c|}{ TC Means (DV) } & \multicolumn{3}{|c|}{ CS Means (DV) } & \multicolumn{2}{|c|}{ SB Means (DV) } \\
\hline & $\mathbf{F}$ & Sig. & & $\mathbf{F}$ & Sig. & $\mathbf{F}$ & Sig. & & $\mathbf{F}$ & Sig. \\
\hline Gender & 4.755 & 0.039 & $*$ & 0.821 & 0.373 & 0.005 & 0.945 & & 0.089 & 0.768 \\
\hline Age & 0.080 & 0.780 & & 0.479 & 0.495 & 0.189 & 0.666 & & 0.696 & 0.411 \\
\hline Education & 2.859 & 0.103 & & 0.048 & 0.828 & 4.826 & 0.034 & $*$ & 0.336 & 0.567 \\
\hline $\begin{array}{l}\text { Academic } \\
\text { Major }\end{array}$ & 0.187 & 0.669 & & 0.567 & 0.458 & 10.918 & 0.002 & $* *$ & 0.320 & 0.576 \\
\hline Academic Year & 2.253 & 0.146 & & 0.905 & 0.350 & 6.329 & 0.016 & $*$ & 0.323 & 0.574 \\
\hline
\end{tabular}

\section{Conclusions, Implications and Recommendations for Future Research}

Overall, the results indicated that there is a significance difference in the role of CMC levels employed (No CMC/F2F, OLS, OLS+SNS) on the level of self-reported of CS within team formation. Also, there is a significance difference in the role of CMC levels employed (No$\mathrm{CMC} / \mathrm{F} 2 \mathrm{~F}, \mathrm{OLS}, \& \mathrm{OLS}+\mathrm{SNS}$ ) on the levels of TP, when controlled for gender. In addition, there is a significance difference in the role of CMC levels employed (No-CMS/F2F, OLS, \& OLS+SNS) on the levels of CS, when controlled for education, academic major and academic year. As with any research study, this study also had some limitations. One of the main significant limitation of this study was the generalizability of the sample. It was limited to an educational environment, so generalizability to a work setting may be limited as well. The university where the study was conducted had limited participant to students taking online classes offered by the School of Health Professions. Therefore, the total population size is limited; it was not limiting the size enough to preclude the study. Another limitation is the CMC that were used. In the future, other CMC can be developed and other SNS can arise and be used more by people than the Facebook platform.

This research study has some implications for the existing body of knowledge in the area of team formation and virtual teams. Organizations are continuing to use the Internet as a source to team formation in virtual environments. The results of this study contributed to the body of knowledge for both practice and research, to help organizations identify ways to support effective team formations. The most interesting finding that this study present is that basically it did not really have a major significance difference between the groups. Originally, the study assumes that TC, $\mathrm{SB}$, TP and CS will have significance difference between the groups. In the end, the study did not get that. With the findings, it is possible that students in Group A (No CMC/F2F) were using mobile devices to communicate between them and the study did not consider this.

This current study compared with other studies like the work of Joe, Tsai, Lin, and Liu (2014) that they used TP as one of the construct in their model to measure team performance to 
determine the success of team formation. This research study outlined a conceptual model for team formation success. Because three out of the four main null hypotheses were not rejected, future research is needed to investigate the construct of TC, SB, TP, and CS. Particularly SB that had a $\mathrm{p}$ value of 0.121 , this indicate that more research is needed to further investigate this particular construct. Probably, future research can try other types of populations. Also, future studies are warranted to increase the validity of the instrument. In addition, more research is needed to expand the sample size and the use of other organizations to increase the generalizability. While this research study concentrated on an educational organization, future research could include assessing other organizations and industries.

\section{References}

Agustín-Blas, L. E., Salcedo-Sanz, S., Ortiz-García, E. G., Portilla-Figueras, A., Pérez-Bellido, Á. M., \& Jiménez-Fernández, S. (2011). Team formation based on group technology: A hybrid grouping genetic algorithm approach. Computers \& Operations Research, 38(2), 484-495.

Anagnostopoulos, A., Becchetti, L., Castillo, C., Gionis, A., \& Leonardi, S. (2012). Online team formation in social networks. Proceedings of the 21st international conference on World Wide Web - WWW'12, USA, p. 839.

Boudreau, M., C., Gefen, D., \& Straub, D. W. (2001). Validation in information systems research: A statement-of-the-art assessment. MIS Quarterly, 25(1), 1-16.

Breakenridge, D. (2008). PR 2.0 new media, new tools, new audience. New Jersey, NY: FT Press.

Chidambaram, L. and Tung, L.L. (2005). Is out of sight, out of mind? An empirical study of social loafing in technology-supported groups. Information Systems Research, 16 (2), 149-168.

Child, D. (2006). The essentials of factor analysis. New York, NY: Continuum International Publishing Group.

Christodoulopoulos, C. E., \& Papanikolaou, K. A. (2007b). Investigation of group formation using low complexity algorithms. 11th International Conference on User Modeling, Greece, 57-60.

Corbitt, G., Gardiner, L., \& Wright, L. (2004). A comparison of team developmental stages, trustand performance for virtual versus face-to-face teams. Proceedings of the 37th Hawaii International Conference on System Sciences, USA, 1-8.

Cronbach, L. J. (1951). Coefficient alpha and the internal structure of tests. Psychometrika, 16(3), 297-334.

Davidow, W. H., \& Malone, W. S. (1992). The virtual corporation. New York, NY: Edward Burlingame Books/HarperBusiness, Harper Collins Publishers. 
Ellington, J. K., Dierdorff, E. C., \& Rubin, R. S. (2014). Decelerating the diminishing returns of citizenship on task performance: the role of social context and interpersonal skill. The Journal of Applied Psychology, 99(4), 748-758.

Fernandez, L. (2009). Personal skills for computing professionals. Computer, 42(10), 110-111.

Fransen, J., Kirschner, P. a., \& Erkens, G. (2011). Mediating team effectiveness in the context of collaborative learning: The importance of team and task awareness. Computers in Human Behavior, 27(3), 1103-1113.

Gefen, D., Straub, D., \& Boudreau, M. (2000). Structural equation modeling and regression: Guidelines for research practice. Communications of the Association for Information Systems, 4(7), 1-77.

Guzzo, R., \& Salas, E. (1995). Team effectiveness and decision making in organizations. San Francisco, CA: Jossey-Bass.

Hanebutte, N. (2013). Applications of computing technology-combining tangible skills and theory in CS0. Journal of Computing Sciences in Colleges, 28(3), 86-93.

Hirschi, T. (1969). The causes of delinquency. Berkeley: University of California Press.

Hogg, M., \& Tinsdale, T. S. (2001). Handbook of Social Psychology: Group Processes. Malden,MA: Blackwell.

Jarvenpaa, S. L., \& Ives, B. (1994). The global network organization of the future: Information management opportunities and challenges. Journal of Management Information Systems, 10(4), 25-57.

Jarvenpaa, S. L., \& Leidner, D. (1999). Communication and trust in global virtual teams. Organization Science, 10(6), 791-815.

Jarvenpaa, S. L., Knoll, K., \& Leidner, D. E. (1998). Is anybody out there ? Antecedents of trust in global virtual teams. Journal of Management Information Systems, 14(4), 29-64.

Joe, S. W., Tsai, Y. H., Lin, C. P., \& Liu, W. T. (2014). Modeling team performance and its determinants in high-tech industries: Future trends of virtual teaming. Technological Forecasting and Social Change, 88, 16-25.

Kerlinger, F. N., \& Lee, H. B. (2000). Foundations of behavioral research (4th ed.). 46 Holt,NY: Harcourt College.

Kristof, A.L., Brown, K. G, Sims Jr., H. P., \& Smith, K. A. (1995). The virtual team: A case study and inductive model. In M. M. Beyerlein, D.A. Johnson and S. T. Beyerlein, (Eds.), Advances in interdisciplinary studies of work teams: Knowledge work in teams, 2, 229253. Greenwich, CT : JAI Press.

Lee, J., \& Lee, Y. (2002). A holistic model of computer abuse within organizations. Information Management \& Computer Security, 10(2), 57-63.

Levy, Y. (2006). The top 10 most valuable online learning activities for graduate MIS students. International Journal of Information and Communication Technology Education, 2(3), 
27-44.

Liccardi, I., Ounnas, A., Pau, R., Massey, E., Kinnunen, P., Lewthwaite, S., Midy, M.-A.,Sarkar, C. (2007). The role of social networks in students' learning experiences. Working group reports on ITiCSE on Innovation and technology in computer science education ITiCSE-WGR '07, USA, 224-237.

Lin, C., Standing, C., \& Liu, Y. (2008). A model to develop effective virtual teams. Decision Support Systems, 45(4), 1031-1045.

Lipnack, J., \& Stamps, J. (1997). Virtual teams: Reaching across space, time, and organizations with technology. New York, NY: John Wiley \& Sons, Inc.

London, M. (2001). How people evaluate others in organizations. New Jersey: Routledge Taylor\& Francis Group.

Malhotra, A., Majchrzak, A., \& Rosen, B. (2007). Leading virtual teams. The Academy of Management Perspectives, 21(1), 60-71.

Mangione, T. W. (1995). Mail surveys: Improving the quality. Thousand Oaks, Calif.: Sage Publications Inc.

Martins, L. L., Gilson, L. L., \& Maynard, M. T. (2004). Virtual teams: What do we know and where do we go from here? Journal of Management, 30(6), 805-835.

Maynard, M., \& Mathieu, J. (2012). Something (s) old and something (s) new: Modeling drivers of global virtual team effectiveness. Journal of Organizational Behavior, 33(3), 342-365.

McMillian, S., \& Morrison, M. (2006). Coming of age with the Internet: A qualitative exploration of how the Internet has become an integral part of young people's lives. New Media \& Society, 8, 73-95.

Mertler, C. A., \& Vannatta, R. A. (2013). Advanced and multivariate statistical methods, 5th edition. Glendale, CA: Pyrczak Publishing.

Miles, R. E., \& Snow, C. C. (1986). Organizations: New concepts for new forms. California Management Review, 18(3), 62-73.

Mowshowitz, A. (1997). Virtual organization. Communications of the ACM, 40(9), 30-37.

Munkvold, B., \& Zigurs, I. (2007). Process and technology challenges in swift-starting virtual teams. Information \& Management, 44(3), 287-299.

Ounnas, A. (2008). Semantic Web-based group formation for e-learning. ESWC 2008 Ph. D. Symposium, Spain, 51-55.

Paul, S., \& Ray, S. (2009). Cultural diversity, perception of work atmosphere, and task conflict in collaboration technology supported global virtual teams: Findings from a laboratory experiment. 42nd Hawaii International Conference on System Sciences, USA, 1-10. 
Porter, S., \& Whitcomb, E. M. (2003). The impact of contact type on Web survey response rate. Public Opinion Quarterly, 67, 579-588.

Powell, A., Piccoli, G., \& Ives, B. (2004). Virtual teams: A review of current literature and directions for future research, The Database for Advances in Information Systems, 35(1), 6-36.

Pratt, T. C., Franklin, T. W., \& Gau, J. M. (2011). Key ideas in criminology and criminal justice. California, USA: Sage Publications Inc.

Quitney, J., \& Rainie, L. (2010). The future of social relations. Pew Research Center's Internet \& American Life Project. Retrieved from http://pewinternet.org/ /media//Files/Reports/2010/PIP_Future_of_Internet 2010_social_relations.pdf

Salisbury, W., Carte, T., \& Chidambaram, L. (2006). Cohesion in virtual teams: Validating the perceived cohesion scale in a distributed setting. Database for Advances in Information Systems, 37(2-3), 147-155.

Schwanda, V., Barron, K., Lien, J., Schroeder, G., Vernon, A., \& Hancock, J. (2011). Temporal patterns of cohesiveness in virtual groups. Proceedings of the ACM 2011 conference on Computer supported cooperative work, 709-712.

Shin, S. Y., \& Park, W. W. (2009). Moderating effects of team cohesiveness in competencyperformance relationships: A multi-level study. Journal of Behavioral Studies in Business, 1, 1-15.

Sproull, L., \& Kiesler, S. (1986). Reducing social context cues: Electronic mail in organizational communication. Management Science, 32(11), 1492-1512.

Torkzadeh, G., \& Lee, J. (2003). Measures of perceived end-user computing skills. Information \& Management, 40(7), 607-615.

Triplett, N. (1898). The dynamogenic factors in pacemaking and competition. The American journal of psychology, 9(4), 507-533.

Turel, O., \& Zhang, Y. (2010). Does virtual team composition matter? Trait and problem-solving configuration effects on team performance. Behaviour \& Information Technology, 29(4), $363-375$.

Wever, B., Mechant, P., Veevaete, P., \& Hauttekeete, L. (2007). E-Learning 2.0: Social software for educational use. Ninth IEEE International Symposium on Multimedia Workshops (ISMW 2007), USA, 511-516. 


\section{Appendix A. Summary of Hypotheses Results}

\begin{abstract}
Hypotheses
H1: There will be no significant difference in the role of CMC levels employed (No CMC/F2F, OLS, OLS+SNS) on the level of $T P$ in team formation.

H2: There will be no significant difference in the role of CMC levels employed (No-CMC/F $2 F, O L S, O L S+S N S)$ on the level of perception of cohesion in team formation.
\end{abstract}

H3: There will be no significant difference in the role of CMC levels employed (No CMC/F2F, OLS, OLS+SNS) on the level of perception of $S B$ in team formation.

H4: There will be no significant difference in the role of CMC levels employed (No CMC/F2F, OLS, OLS+SNS) on the level of perception of $C S$ in team formation.

H5a: There will be no significant difference in the role of CMC levels employed (No-CMC/F2F, OLS, OLS+SNS) on the levels of $T P$, perception of cohesion, perception of $S B$, and perception of $C S$ when controlled for gender.

$\boldsymbol{H 5 b}$ : There will be no significant difference in the role of CMC levels employed (No-CMC/F $2 F, O L S, O L S+S N S)$ on the levels of $T P$, perception of cohesion, perception of $S B$, and perception of $C S$ when controlled for age.

H5c: There will be no significant difference in the role of CMC levels employed (No-CMC/F2F, OLS, OLS+SNS) on the levels of $T P$, perception of cohesion, perception of $S B$, and perception of $C S$ when controlled for education level.

H5d: There will be no significant difference in the role of CMC levels employed (No-CMC/F2F, OLS, OLS+SNS) on the levels of $T P$, perception of cohesion, perception of $S B$, and perception of $C S$ when controlled for academic major.

H5e: There will be no significant difference in the role of CMC levels employed (No-CMC/F2F, OLS, OLS+SNS) on the levels of $T P$, perception of cohesion, perception of $S B$, and perception of $C S$ when controlled for academic year.

\section{Results}

Fail to reject

Fail to reject

Fail to reject

Rejected

Partially Rejected (For TP construct rejected. For cohesion, SB and CS construct, not rejected)

Fail to reject

Partially Rejected (For CS construct rejected. For cohesion, $\mathrm{SB}$ and TP construct, not rejected)

Partially Rejected (For CS construct rejected. For cohesion, SB and TP construct, not rejected)

Partially Rejected (For CS construct rejected. For cohesion, $\mathrm{SB}$ and TP construct, not rejected) 


\section{Authors' Biographies}

Eliel Melon, Ph.D. is the Director of IT and a Lecturer of the School of Health Professions in the Medical Sciences Campus at the University of Puerto Rico. He has a Ph.D. in Information Systems from the College of Engineering and Computing at Nova Southeastern University. He also holds a Master in Business Administration with a concentration in Technology Management. Also, he holds a Bachelor's of Science degree in Computational Mathematics from the University of Puerto Rico. He has worked in the technology industry for 18 years, holding several positions including Associate Director of IT, Network Administration, Database Administration and a Programmer. Dr. Melon's research interests include Cybersecurity, Social Networks in e-learning systems, social engineering awareness, cyber threat prevention, privacy in Information Systems, Health Informatics, among others. He has taught several courses that include: Health Information Systems, Analysis, Design and Development of Health Information Systems, Introduction to Computers and Microcomputers applied to Health Sciences. He has participate and publish in several conference proceedings. Also, he has served as a reviewer in several conferences like IEEE SoutheastCon 2015, KM Conference 2014 and $33^{\text {rd }}$ Annual Research and Education Forum.

Yair Levy, Ph.D. is a Professor of Information Systems and Cybersecurity at the College of Engineering and Computing, at Nova Southeastern University, the Director of the Center for eLearning Security Research (CeLSR), and chair of the Information Security Faculty Group at the college. He joined the university in 2003, was promoted to an Associate Professor in 2007, and to full Professor in 2012. During the mid to late 1990s, Dr. Levy assisted NASA to develop elearning platforms as well as manage Internet and Web infrastructures. He earned his undergraduate degree in Aerospace Engineering from the Technion (Israel Institute of Technology). He received his Masters of Business Administration (MBA) with Management Information Systems (MIS) concentration and Ph.D. in MIS from Florida International University. He heads the Levy CyLab, which conducts innovative research from the humancentric lens of four key research areas Cybersecurity, User-authentication, Privacy, and Skills (CUPS), as well as their interconnections. He authored over 60 articles, three book chapters, one book, and his publications have been cited for over 1,400 times by other scholarly research. Dr. Levy has been an active member of the US Secret Service (USSS)'s - Miami Electronic Crimes Task Force (MECTF). He was trained by the Federal Bureau of Investigation (FBI) on various topics, and actively serves as a member of the FBI/InfraGard, and consults the FBI/Cyber Task Force (CTF). Dr. Levy serves on the national Joint Task Force of Cybersecurity Education, as well as other national initiatives related to cybersecurity workforce, education, and research. He is also a frequent invited keynote speaker at national and international meetings, as well as regular media interviews as a Subject Matter Expert (SME) on cybersecurity topics. Find out more about Dr. Levy and his research lab via: http://cec.nova.edu/ levyy/

Laurie P. Dringus, Ph.D. is a Professor of Information Systems at the College of Engineering and Computing at Nova Southeastern University (NSU). Dr. Dringus earned her undergraduate and master's degrees in psychology, and her Ph.D. in Information Systems, from NSU. She has taught over 150 graduate level courses online and has been involved in distance learning and online learning since 1983. She was part of the pioneering group at NSU in online learning that started in 1983. She also served as director of one of the first online master's programs at NSU 
established in the mid-80s. As a full-time faculty member since 1991, her research and teaching interests continue to focus on user-centered design and information systems, delivery and support of online learning environments, and computer-mediated technology and interactivity. Dr. Dringus is a member of several professional associations and presents at several associated conferences, including those sponsored by Sloan-C, AERA, ACM, and IEEE. She has authored approximately 65 articles and presentations in the area of human-computer interaction and online learning environments. Currently, her research relates to studying the effects of temporal transitions on participation flow in asynchronous discussion forums. She is also conducting research on the effective use of audio to enhance teacher presence in online discussions. Her future creative endeavors include developing new graduate courses and continuing her research in social networking, computer-mediated communication, and communities of practice. Since 1998, Dr. Dringus has served as Editor-in-Chief of The Internet and Higher Education, a refereed international journal published quarterly by Elsevier. 